\section{SANDIA REPORT}

SAND97-0615 • UC-910

Unlimited Release

Printed March 1997 a

MMP 081897

OSTI

\title{
Photonic Integrated Circuit for All-Optical Millimeter-Wave Signal Generation
}

G. Allen Vawter, Alan Mar, Vince Hietala, John Zolper

Prepared by

Sandia National Laboratories

Albuquerque, New Mexico 87185 and Livermore, California 94550

Sandia is a multiprogram taboratory operated by Sandia

Corporation, a Lockheed Martin Company, for the United States

Department of Energy under Contract DE-ACO4-94AL85000.

Approved for public release; distribution ss unilinited

Tin Sandia National Laboratories
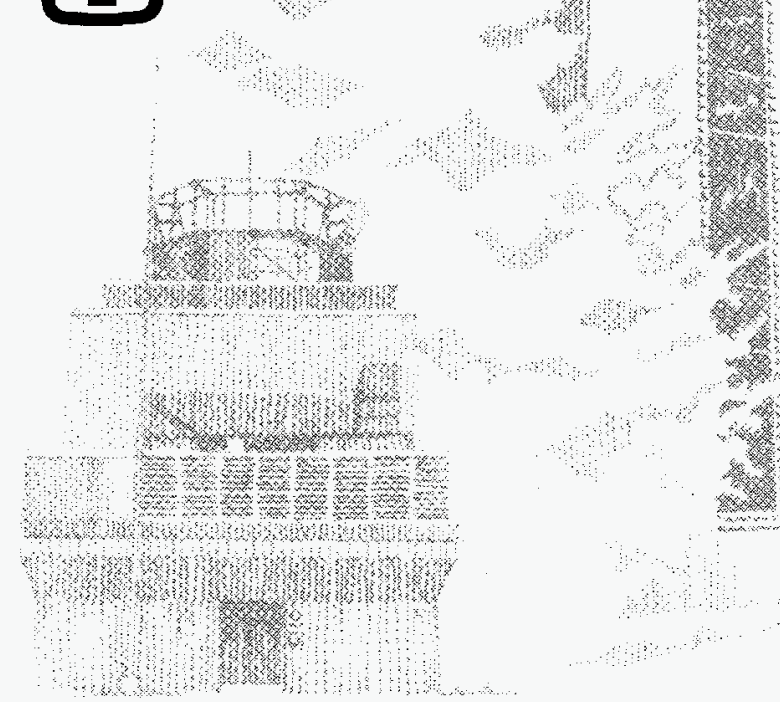
Issued by Sandia National Laboratories, operated for the United States Department of Energy by Sandia Corporation.

NOTICE: This report was prepared as an account of work sponsored by an agency of the United States Government. Neither the United States Government nor any agency thereof, nor any of their employees, nor any of their contractors, subcontractors, or their employees, makes any warranty, express or implied, or assumes any legal liability or responsibility for the accuracy, completeness, or usefulness of any information, apparatus, product, or process disclosed, or represents that its use would not infringe privately owned rights. Reference herein to any specific commercial product, process, or service by trade name, trademark, manufacturer, or otherwise, does not necessarily constitute or imply its endorsement, recommendation, or favoring by the United States Government, any agency thereof, or any of their contractors or subcontractors. The views and opinions expressed herein do not necessarily state or reflect those of the United States Government, any agency thereof, or any of their contractors.

Printed in the United States of America. This report has been reproduced directly from the best available copy.

Available to DOE and DOE contractors from Office of Scientific and Technical Information

P.O. Box 62

Oak Ridge, TN 37831

Prices available from (615) 576-8401, FTS 626-8401

Aveilable to the public from

National Technical Information Service

U.S. Department of Commerce

5285 Port Royal Rd

Springfield, VA 22161

NTIS price codes

Printed copy: A03

Microfiche copy: $\mathrm{A} 01$ 


\section{DISCLAIMER}

Portions of this document may be illegible in electronic image products. Images are produced from the best available original document. 
SAND97-0615

Distribution

Unlimited Release

Printed March 1997

Category UC-910

\title{
Photonic Integrated Circuit for All-Optical Millimeter-Wave Signal Generation
}

\author{
G. Allen Vawter \\ Compound Semiconductor Materials \& Processes \\ Alan Mar \\ High Power Electromagnetics Department \\ Vince Hietala \\ Advanced Devices \& Applications Department \\ John Zolper \\ Compound Semiconductor Materials \& Processes \\ Sandia National Laboratories \\ P.O. Box 5800 \\ Albuquerque, NM 87185-0603
}

\begin{abstract}
Generation of millimeter-wave electronic signals and power is required for highfrequency communication links, RADAR, remote sensing and other applications. However, in the 30 to $300 \mathrm{GHz}$ mm-wave regime, signal sources are bulky and inefficient. All-optical generation of mm-wave signals promises to improve efficiency to as much as 30 to 50 percent with output power as high as $100 \mathrm{~mW}$. All of this may be achieved while taking advantage of the benefits of monolithic integration to reduce the overall size to that of a single semiconductor chip only a fraction of a square centimeter in size. This report summarizes the development of the first monolithically integrated all-optical mm-wave signal generator ever built. The design integrates a mode-locked semiconductor ring diode laser with an optical amplifier and high-speed photodetector into a single optical integrated circuit. Frequency generation is demonstrated at 30,60 and $90 \mathrm{Ghz}$.
\end{abstract}




\section{Contents}

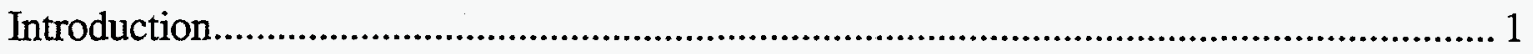

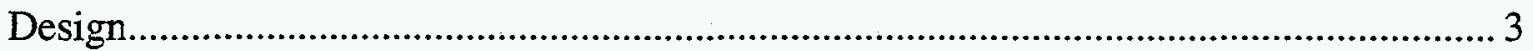

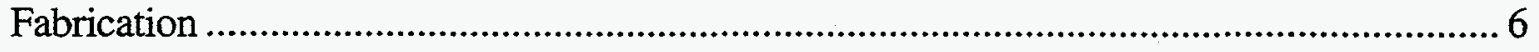

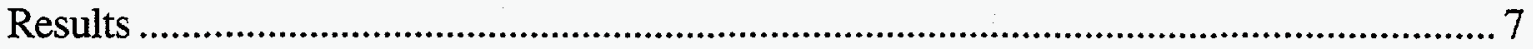

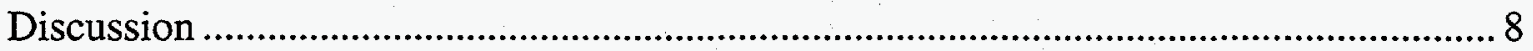

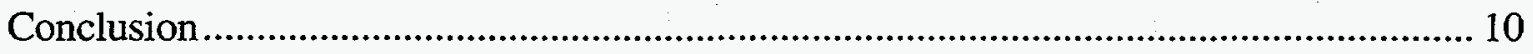

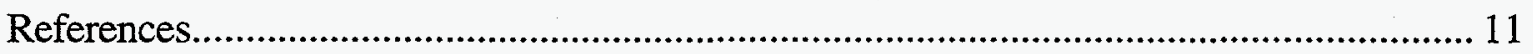

Figures

Figure 1: Configuration of mode-locked ring laser without output coupling of light..........2

Figure 2: Configuration of mode-locked ring laser with output coupling of light to an optical amplifier and photodetector. ............................................................................ 3

Figure 3: Schematic of actual mm-wave generation circuit............................................ 4

Figure 4: Cross-section views of the three principle circuit elements comprising the alloptical mum-wave signal generator. ........................................................................ 5

Figure 5: Electron micrograph view of complete all-optical mm-wave signal generation

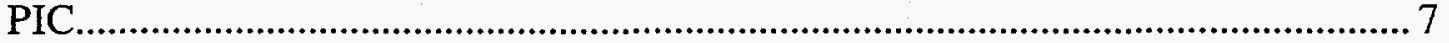

Figure 6: Measured performance of three different mm-wave signal generation PICs....... 8

\section{Tables}

Table 1: Operating currents and voltages for selected mm-wave generation PICs.............. 7 


\section{Summary}

We demonstrate the first compact photonic integrated circuit (PIC) for generation of mm-wave frequencies. This new PIC integrates a passively mode-locked semiconductor ring laser, optical amplifier and high-speed photodiode for generation, amplification and detection of an optical pulse train with 30 to $90 \mathrm{GHz}$ pulse-repetition frequency. Output of the PIC is an electrical signal, generated by the photodiode, whose fundamental frequency is the pulse repetition rate of the mode-locked laser. The circuit uses a novel waveguide photodiode (WGPD) integrated with a mm-wave transmission line specifically designed for high-speed operation and signal extraction on a heavily-doped GaAs substrate.

The mm-wave generation PIC uses ( $\mathrm{Al}, \mathrm{Ga}) \mathrm{As}$ double-heterostructure rib waveguides with a single-quantum-well active region. Multi-lateral-mode ring waveguides with Yjunction output couplers are etched to form passively mode-locked lasers monolithically integrated with an optical amplification section and WGPD at the laser output. Pulse repetition frequency is fixed by the ring diameter and saturable absorber configuration; we have demonstrate 30,60 and $90 \mathrm{GHz}$ circuits. The WGPD is formed using a trench etch around the rib waveguide and is integrated with an electrical transmission line for efficient removal of the output signal.

Fundamental pulse repetition frequency of the 860,430 and $290 \mu \mathrm{m}$ diameter rings were $29.1,57.5$ and $85.2 \mathrm{GHz}$ respectively. Frequency generation close to the desired value was achieved for all three laser diameters. Peak mm-wave power levels are $-12,-23$ and $-27 \mathrm{dBm}$ at $29.1,57.5$ and $85.2 \mathrm{GHz}$ respectively.

This circuit demonstrates the feasibility of mm-wave signal generation using a modelocked ring laser PIC. Output power of these circuits is influenced by a number of factors including the internal circulating power of the ring, the amount of power coupled out of the ring, the gain of the amplifier, and the efficiency of the photodiode. PICs using this concept could be used in a wide variety of applications where a very compact, lightweight $\mathrm{mm}$-wave source is required. 


\section{Nomenclature}

$\begin{array}{ll}\mathrm{Al}_{\mathrm{x}} \mathrm{Ga}_{1-\mathrm{x}} \mathrm{As} & \text { Aluminum Gallium Arsenide, } \mathrm{x} \text { determines the proportion of } \\ \mathrm{CW} & \text { Aluminum to Gallium } \\ \mathrm{FWHM} & \text { Continuous Wave } \\ \mathrm{GaAs} & \text { Full Width at Half Maximum } \\ \mathrm{GRINSCH}-\mathrm{SQW} & \text { Gallium Arsenide } \\ \mathrm{Gunn} & \text { Graded-index separate-confinement heterostructure } \\ \mathrm{IMPATT} & \text { Gunn diode } \\ \text { PIC } & \text { Impact Ionization Avalanche Transit Time diode } \\ \mathrm{RIBE} & \text { Photonic Integrated Circuit } \\ \mathrm{RMS} & \text { Reactive Ion Beam Etching } \\ \mathrm{TEM} & \text { Root Mean Square } \\ \mathrm{WGPD} & \text { Transverse Electromagnetic } \\ & \text { Waveguide Photodiode } \\ & \\ { }^{\circ} \mathrm{C} & \text { degrees celsius } \\ \mathrm{c} & \text { speed of light in vacuum } \\ \mathrm{d} & \text { ring diameter } \\ \mathrm{dB} & \text { logarithmic relative power scale } \\ \mathrm{dBm} & \text { logarithmic power scale relative to } 1 \mathrm{~mW} \\ \mathrm{GHz} & \text { Giga Hertz }=10^{9} \text { cycles per second } \\ \mathrm{MHz} & \text { Mega Hertz }=10^{6} \text { cycles per second } \\ \mathrm{mm} & \text { millimeter }=10^{-3} \text { meters } \\ \mathrm{mW} & \text { milliwatts }=10^{-3} \text { watt } \\ \mathrm{n}_{\text {eff }} & \text { modal effective refractive index } \\ \mathrm{nm} & \text { nanometer }=10^{-9} \text { meters } \\ \mathrm{ns} & \text { nano second }=10^{-9} \text { seconds } \\ \mathrm{Ohm} & \text { unit of resistance } \\ \mathrm{psec} & \text { pico second }=10^{-12} \text { seconds } \\ f & \text { pulse repetition frequency } \\ \pi & \text { pi }=3.1415926 \\ \mathrm{~s} & \text { seconds } \\ \mu \mathrm{m} & \text { micro meter }=10^{-6} \text { meters } \\ & \end{array}$




\section{All Optical Millimeter-Wave Signal Generation Using an Integrated Mode-Locked Semiconductor Laser and Photodiode}

\section{Introduction}

Presently, mm-wave sources are typically formed with Gunn or IMPATT diodes in a $\mathrm{mm}$-wave resonant cavity. At frequencies near $100 \mathrm{GHz}$, the output power and efficiency of these sources is low (typically $10 \mathrm{~mW}$ output power and $\leq 1 \%$ efficiency); and higher frequencies are only accessible by frequency mixing. Demonstration of passive modelocking of semiconductor ring lasers at high pulse repetition rates 1 suggests the possibility of an photonic integrated circuit (PIC) comprising a mode-locked ring laser and travelingwave photodiode $2-4$ (TWPD) for direct generation of $\mathrm{mm}$-wave electrical signals. Such a PIC could be compact and relatively efficient compared to current technology and operate in the regime above $60 \mathrm{GHz}$ where existing semiconductor-based mm-wave sources are inefficient or simply non-existent.

This research effort demonstrates a new all-optical technology for the generation of millimeter waves at frequencies $\geq 50 \mathrm{GHz}$. This new PIC-based technology has the potential to provide up to an order of magnitude improvement in output power and efficiency over current mm-wave technology using Gunn or IMPATT diodes. PIC technology further allows extension to higher frequencies and a substantial reduction in package size not accessible with conventional semiconductor approaches.

Our approach for mm-wave generation using PIC technology is based on the use of an resonant optical cavity (in the form of a passively mode-locked ring diode laser) to generate a continuous optical pulse train at mm-wave frequencies. The optical pulse train is then sent to a photodiode such that the photodiode current is proportional to the light intensity within the response bandwidth of the diode. Since mode-locked ring laser pulse repetition frequencies 1 and TWPD response bandwidths ${ }^{3}$ have been demonstrated up to $172 \mathrm{GHz}$, frequency sources well into the hundreds of $\mathrm{GHz}$ may be fabricated. When a mode-locked diode laser is used, the periodic optical waveform is a train of pulses at the mode-locking frequency. In the case of such non-sinusoidal light sources as a mode-locked laser, the diode itself may be designed to act as a low-pass filter to remove any unwanted spectral content above the mode-locking frequency. 


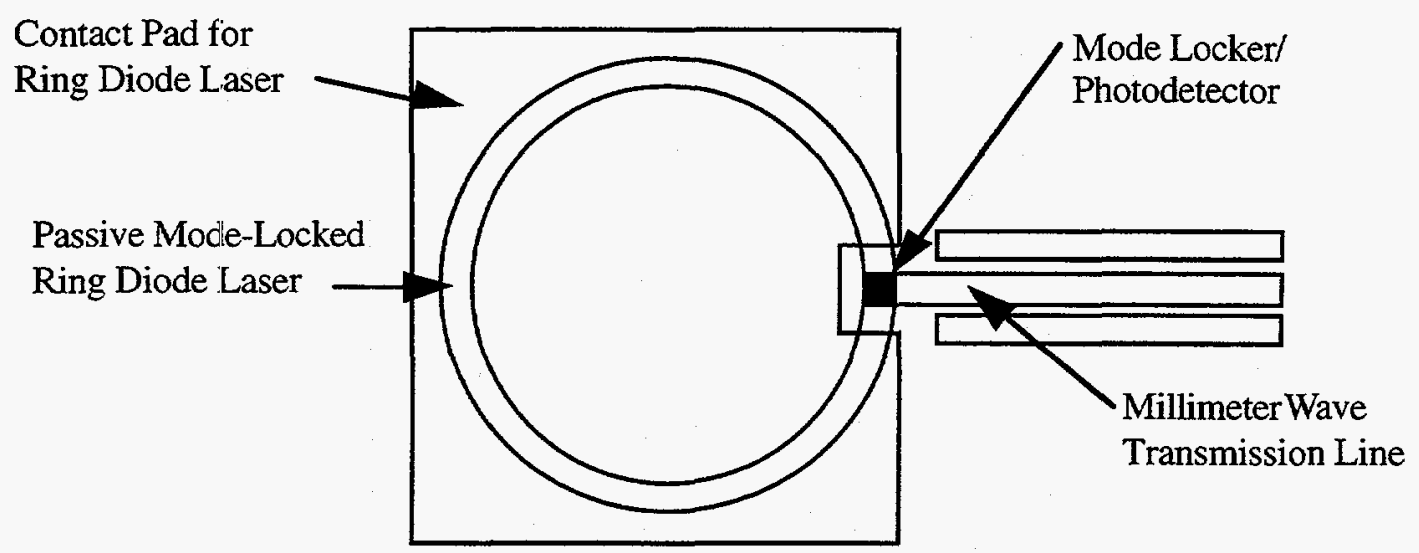

Figure 1: Configuration of mode-locked ring laser without output coupling of light. The mm-wave signal is taken directly from the saturable absorber.

The simplest scheme for mm-wave generation is shown schematically in figure 1 . Here, a closed-ring GaAs/AlGaAs diode laser is used for low-threshold, high-power direct-current (d. c.) operation. A small region of the ring $(10-50 \mu \mathrm{m})$ is separately contacted, and reverse-biased (d. c.) to form a saturable absorber. This saturable absorber results in a passive mode locking of the lasing in the ring cavity (in both ring directions) generating a continuous train of short $(\approx 1 \mathrm{ps})$ lasing light pulses in the ring cavity. The pulse train frequency is determined by the light transit time around the ring cavity (a 300$\mu \mathrm{m}$-diameter ring would generate a pulse train at $88 \mathrm{GHz}$ ); and the pulse width is determined by the light transit time through the mode locker $(\approx 1 \mathrm{ps})$. For minimum cavity loss, the two counter propagating lasing pulses arrive at the saturable absorber simultaneously ('colliding-pulse' mode locking), which stabilizes the pulse train and results in the shortest pulse width. This reverse-biased saturable absorber also functions as a high-speed photodetector converting a fraction the lasing pulse train into a $\mathrm{mm}$-wave electrical output. Output power drawn from the absorber will be limited by power dissipation and heating limits within the small absorbing section. As seen in the figure, a mm-wave transmission line will be used to propagate the absorbed power to a high-speed probe for detection. This scheme minimizes parasitic loading effects which might otherwise reduce the output power of the absorber section.

A second PIC design with the potential for generation of a higher-power $(\geq 100 \mathrm{~mW})$ $\mathrm{mm}$-wave output is shown in figure 2 . Here, the mode-locked ring laser uses a multimode $\mathrm{Y}$-junction, created by reactive-ion-beam etching, to couple lasing output into an optical waveguide amplifier for $(>10 \mathrm{~dB})$ gain. A direct-waveguide photodetector (WGPD) with the same epi structure converts the lasing pulse train emerging from the amplifier to a mm-wave electrical output. The available gain of the amplifier and the high efficiency of the WGPD permit higher signal levels compared to direct detection of the saturable absorber current. Maximizing the power out of the circuit will require optimization of the fraction of light coupled out of the laser by the Y-junction or other output coupler. With minor modifications, this scheme can be extended to even higher frequency, generating a mm-wave electrical output at twice the frequency of the modelocked ring laser. To do this, the passive mode locker is located at $90^{\circ}$ around the ring from 
the output coupler. In this way, the two counter propagating mode-locked pulse trains in the ring cavity will be delayed by one-half period at the output coupler resulting in an output pulse train with twice the ring cavity frequency.

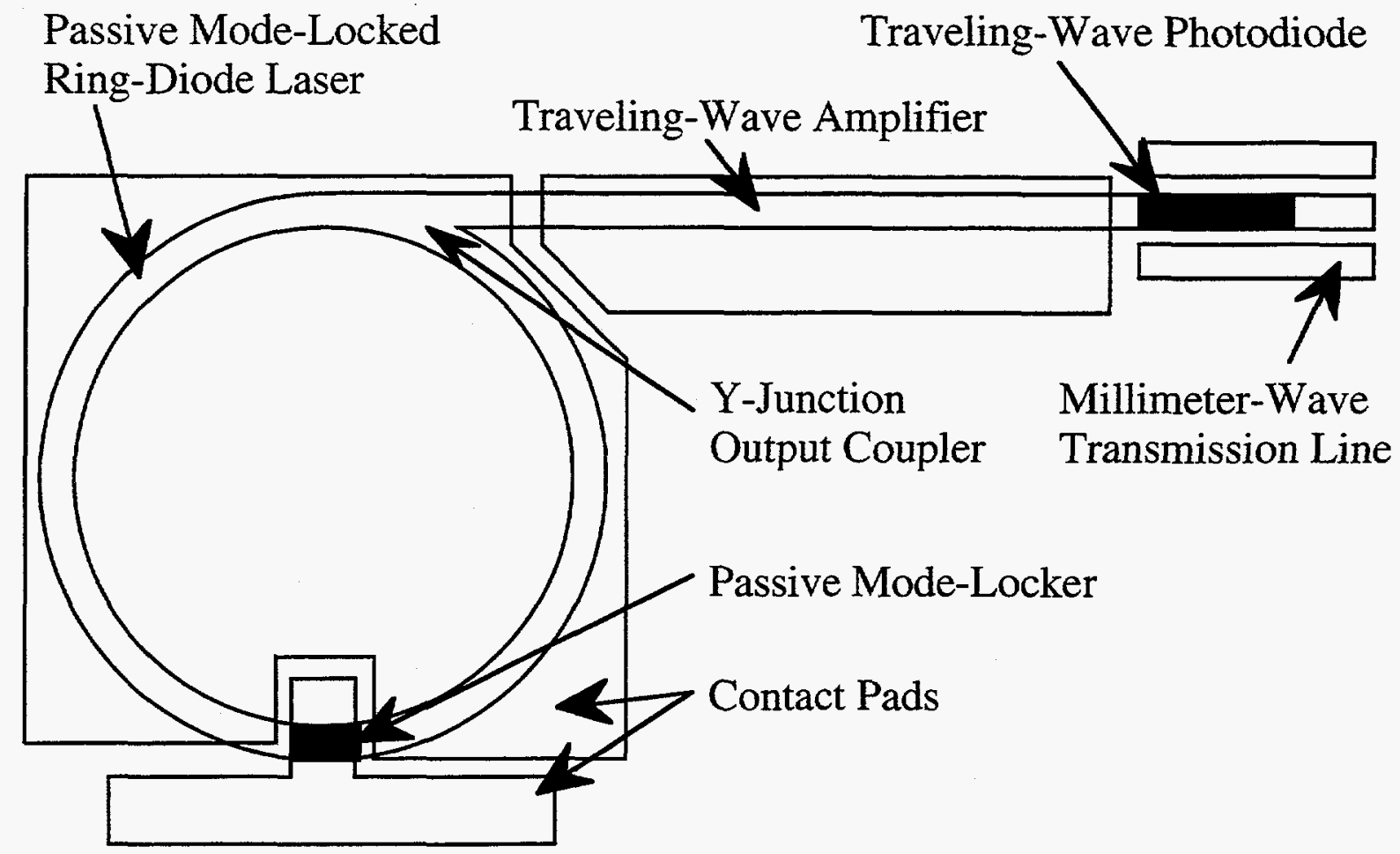

Figure 2: Configuration of mode-locked ring laser with output coupling of light to an optical amplifier and photodetector. The mm-wave signal is taken from the photodetector.

\section{Design}

As described in general terms above, this report summarizes a new PIC integrating a passive mode-locked ring laser with an optical amplifier and a high-speed waveguide photodetector (WGPD) for mm-wave frequency generation. The feasibility of this new PIC is evaluated and electrical output characteristics measured at 30,60 and $90 \mathrm{GHz}$.

To fabricate an PIC for mm-wave frequency generation we have integrated an AlGaAs semiconductor ring laser with an optical amplifier, high-speed WGPD and 50-Ohm transmission line for removal of the electrical signal. A WGPD was chosen rather than a velocity-matched TWPD so that the OEIC requires only one epitaxial growth sequence. The pn-junction design was optimized for laser and amplifier operation and does not have a large enough depletion width to accommodate a velocity-matched photodetector. The pulse 
repetition frequency, $f$, of the mode-locked laser is fixed by the cavity round trip time which is determined by the diameter of the ring according to (1)

$$
f=\frac{c}{n_{\text {eff }}} \times \frac{1}{\pi d}
$$

where $c$ is the vacuum speed of light, $n_{\text {eff }}$ the group effective refractive index of the ring waveguide and $\mathrm{d}$ the ring diameter. Rings of nominally 30,60 and $90 \mathrm{GHz}$ pulserepetition frequency were designed having diameters of 860,430 and $290 \mu \mathrm{m}$ respectively using the known $86 \mathrm{GHz}$ rate for a $300 \mu \mathrm{m}$ ring employing $6-\mu \mathrm{m}$ wide multilateral-moded rib waveguides. Figure (3) illustrates the configuration of the three circuit elements for 60 an $90 \mathrm{GHz}$ signals. Light output from the ring laser is coupled by an equal-width branching Y-junction into a 1-mm long waveguide optical amplifier. The amplifier provides optical gain to the pulse train prior to coupling the pulses into the WGPD where the pulse train is converted into an electrical signal whose frequency spectrum has a fundamental component at the pulse repetition frequency. Figure (4) shows cross sections of the four circuit elements. Large diameter rings were tested using a saturable absorber with a high-speed transmission-line contact similar to figure 1 . The $30 \mathrm{GHz}$ electrical output signal was taken directly from the saturable absorber.

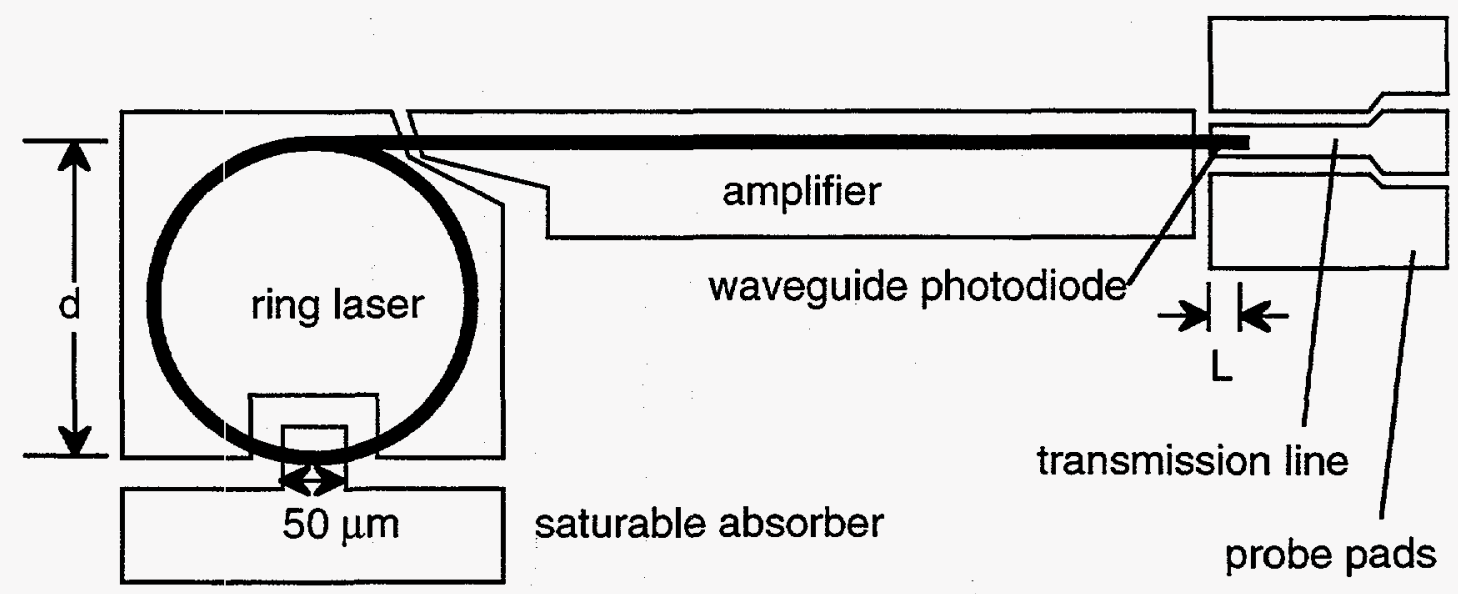

Figure 3: Schematic of actual mm-wave generation circuit. 


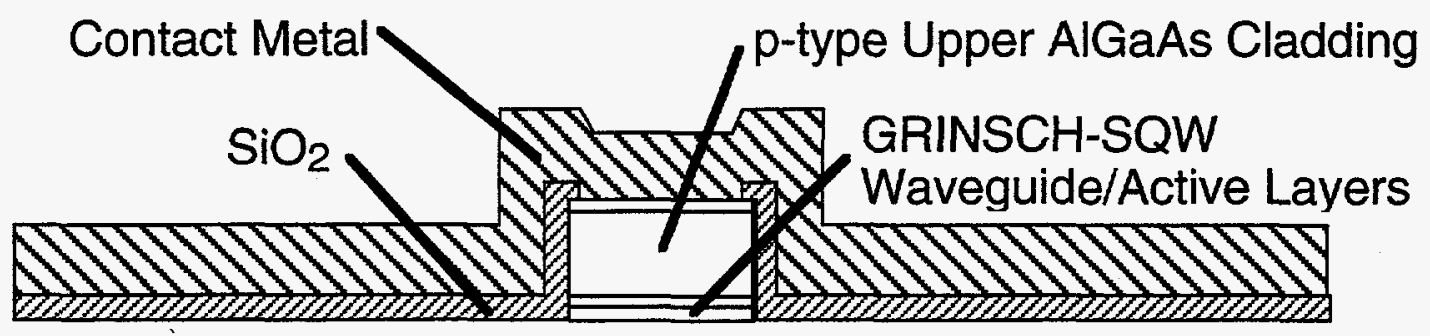

n-type Lower AIGaAs Cladding

(a)

$n+$ GaAs Substrate

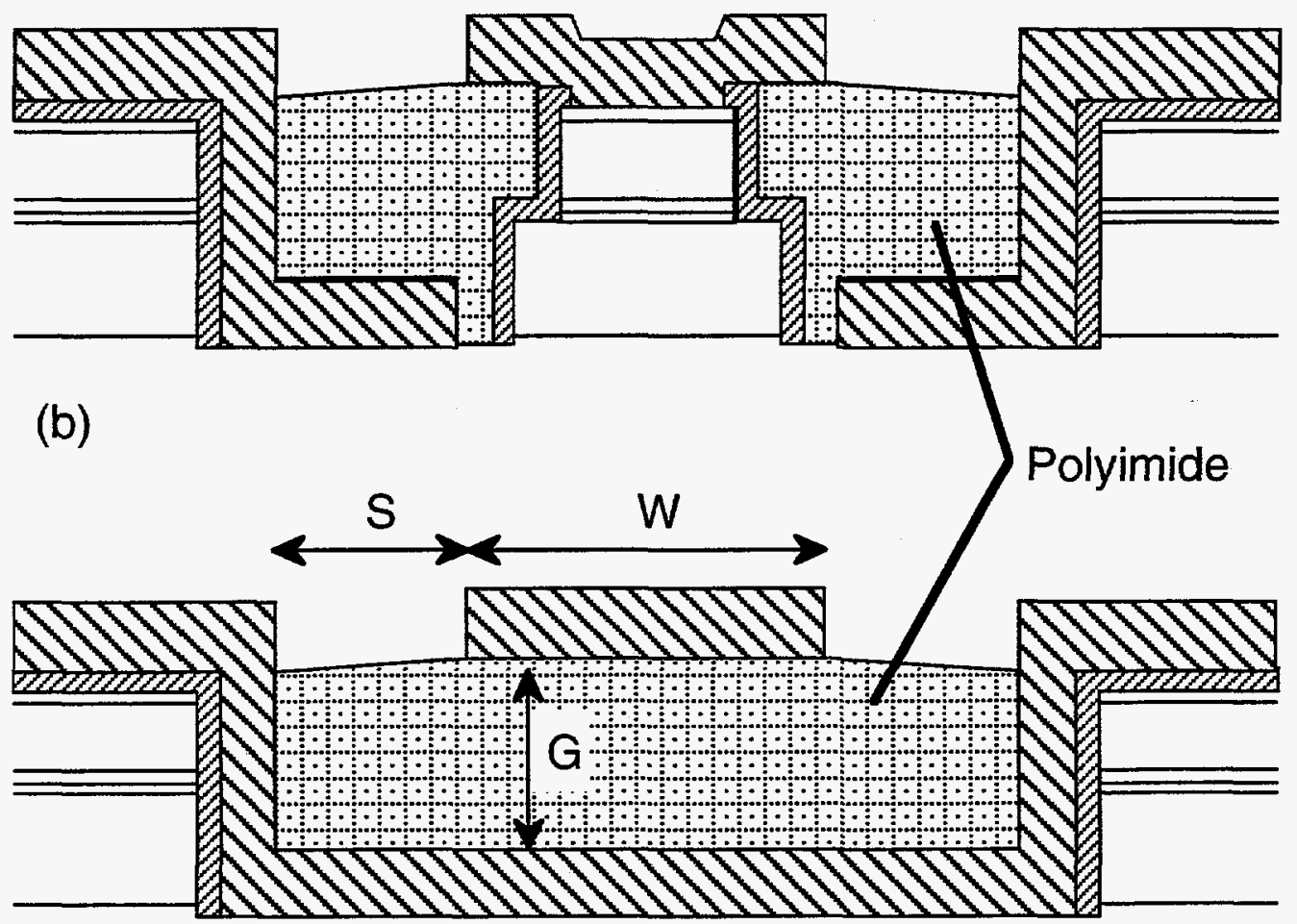

(c)

Figure 4: Cross-section views of the three principle circuit elements comprising the all-optical mm-wave signal generator. (a) Laser and amplifier active waveguide. (b) Waveguide photodiode. (c) Millimeterwave transmission line.

Since the n-type doped substrate would cause severe capacitive loading of a conventional photodiode and bond pad, particular care was taken to design the WGPD for high speed operation. The WGPD, Fig. (4b), has a small active area and is coupled directly into a $50 \mathrm{Ohm}$ transmission line, Fig. (4c), used to transport electrical signals to the 
ground-signal-ground contact pads. Dimensions of the transmission line ( $\mathrm{W}=12 \mu \mathrm{m}, \mathrm{S}$ $=5 \mu \mathrm{m}, \mathrm{G}=10 \mu \mathrm{m}$ ) were selected to give low loss and an approximate $50 \mathrm{Ohm}$ characteristic impedance. Simulated characteristic impedance, loss and effective refractive index of the RF transmission line at $100 \mathrm{GHz}$ frequency using a quasi-TEM transmissionline model are $47.35-\mathrm{j} 1.21 \mathrm{Ohms}, 0.76 \mathrm{~dB} / \mathrm{mm}$, and 1.629 respectively. The WGPD is fabricated by inserting the pn-junction waveguide material between the center electrode and ground plane of the transmission line. The additional loss and capacitance of the diode lowers the characteristic impedance to $13.5+\mathrm{j} 0.63$ and raises the effective refractive index to $\sim 7$ in the 30 to $100 \mathrm{GHz}$ frequency range. The electrical wavelength in the WGPD is $\sim 430 \mu \mathrm{m}$ at $100 \mathrm{GHz}$. The impedance mismatch, high effective index and electrical wavelength suggest that device lengths below $200 \mu \mathrm{m}$ are adequately viewed as lumped photodiodes. In order to partially optimize the detector quantum efficiency at each frequency, shorter detectors are used with the higher frequency lasers. Both 10 and $80 \mu \mathrm{m}$ WGPD lengthss were integrated with the 60 and $90 \mathrm{GHz}$ lasers. All detectors are $6 \mu \mathrm{m}$ wide, matching the width of the laser and amplifier waveguides. The reverse-biased quantum well gives an optical absorption coefficient within the waveguide of $430 \mathrm{~dB} / \mathrm{cm}$. At this absorption level $84 \%$ of the light intensity will be absorbed by the photodiode in $180 \mu \mathrm{m}$ of waveguide length. Similarly, $10 \%$ will be absorbed in $10 \mu \mathrm{m}$ and $55 \%$ in 80 $\mu \mathrm{m}$. These values are the upper limit of quantum efficiency, assuming $100 \%$ conversion of absorbed light into current, for the three lengths of WGPD. Although reflection from the etched end of the WGPD could be used to effectively double the efficiency of the shorter devices, such reflections, when coupled back through the amplifier into the ring laser, pose a risk of perturbing or destroying the mode-locking behavior of the laser. As a means to suppress feedback from the WGPD to the laser, the ends of the WGPD waveguides were etched at an angle.

\section{Fabrication}

The epitaxial structure for our mm-wave generation OEIC is a single-quantum-well $(10 \mathrm{~nm})$ graded index separate-confinement-heterostructure in $\mathrm{GaAs} / \mathrm{Al}_{\mathrm{x}} \mathrm{Ga}_{1-\mathrm{x}} \mathrm{As}$ with $\mathrm{x}=0.6$ cladding layers. Oxygen ion implantation of the $\mathrm{p}$-type layers in the regions between circuit elements was used to provide electrical isolation. The implant was annealed at $850^{\circ} \mathrm{C}$ for $30 \mathrm{~s}$ to recover optical transparency while maintaining high-resistivity. 5,6 The 6 - $\mu \mathrm{m}$ wide laser, output coupler, amplifier and WGPD multilateral mode rib waveguides were formed simultaneously by chlorine reactive ion beam etching (RIBE) through the active layer. The deep trench for the WGPD and transmission line was then etched by RIBE. WGPD n-type ohmic contacts and transmission line ground plane metalization were deposited in the trench followed by a polyimide dielectric used to support the p-type WGPD contact and transmission line center electrode. The laser, amplifier and WGPD ptype ohmic contacts and transmission-line center electrode were deposited in a single step. Completed OEICs were tested p-side up without heat sinking. Figure (5) is an SEM image of a complete OEIC. Although the straight amplifier section is broken into two separately contacted sections, all data presented here was taken by wire bonding the two sections together or using two shorted probes and applying a common bias current. 


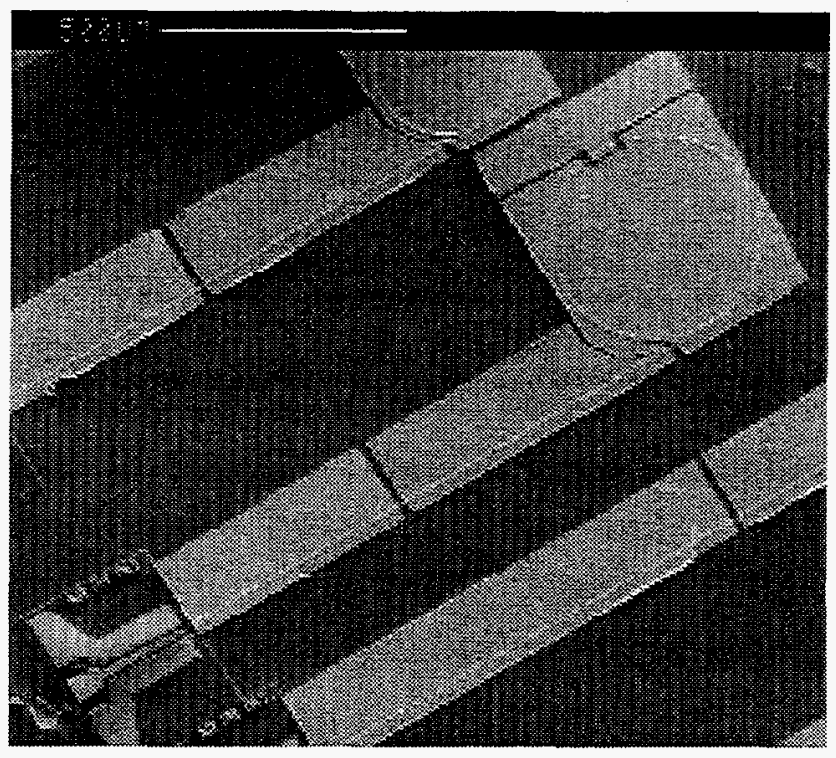

Figure 5: Electron micrograph view of complete all-optical mm-wave signal generation PIC. Total length of the circuit is less than $2 \mathrm{~mm}$. Refer to figure 3 for itemized labeling of PIC elements.

\section{Results}

Testing of the PIC involved identifying the CW lasing threshold current of the ring laser by applying a bias current to the laser and monitoring the amplifier section for photocurrent. Once threshold has been identified a forward bias current is applied to the amplifier with the laser biased above threshold and the amplifier characterized for transparency and gain by monitoring the photocurrent in the WGPD. After measuring the $\mathrm{CW}$ characteristics of the PIC, mode-locking of the ring laser is established by reverse biasing the saturable absorber while monitoring the WGPD using Cascade co-planar probes and an HP8565E spectrum analyzer. Harmonic mixers were used at the input of the spectrum analyzer for heterodyne detection of frequencies above $50 \mathrm{GHz}$. Table 1 details the required bias conditions of the three ring diameters for stable mode-locking.

Table 1: Operating currents and voltages for selected mm-wave generation PICs.

\begin{tabular}{|c|c|c|c|c|}
\hline$\underset{(\mu \mathrm{m})}{\text { Ring Dia. }}$ & $\begin{array}{l}\text { Ring Current } \\
(\mathrm{mA})\end{array}$ & $\begin{array}{l}\text { Absorber Bias } \\
\text { (V) }\end{array}$ & $\begin{array}{l}\text { Amp. Current } \\
\text { (mA) }\end{array}$ & $\begin{array}{l}\text { WGPD Bias } \\
\text { (V) }\end{array}$ \\
\hline 860 & 130 & -2.9 & 70 & -2.9 \\
\hline 430 & 180 & -3.3 & 70 & -18 \\
\hline 290 & 192 & -3.4 & 70 & -17 \\
\hline
\end{tabular}

Output frequency, power and electrical linewidth of each PIC is plotted in Fig. (6). Measured output power and frequency of the 860,430 and $290 \mu \mathrm{m}$ diameter of rings were $-12 \mathrm{dBm}$ at $29.1 \mathrm{GHz},-23 \mathrm{dBm}$ at $57.5 \mathrm{GHz}$ and $-27 \mathrm{dBm} 85.2 \mathrm{GHz}$ respectively. 
Frequency generation close to the desired value was achieved for all three laser diameters. The signals have a typical linewidth of $0.3-1.0 \mathrm{MHz}$. The linewidth is influenced primarily by timing jitter of the pulse train. This jitter was determined by integrating the sideband noise and ranged from about $0.3-1.0$ ns RMS, such values are not unusual for passively mode-locked semiconductor lasers.

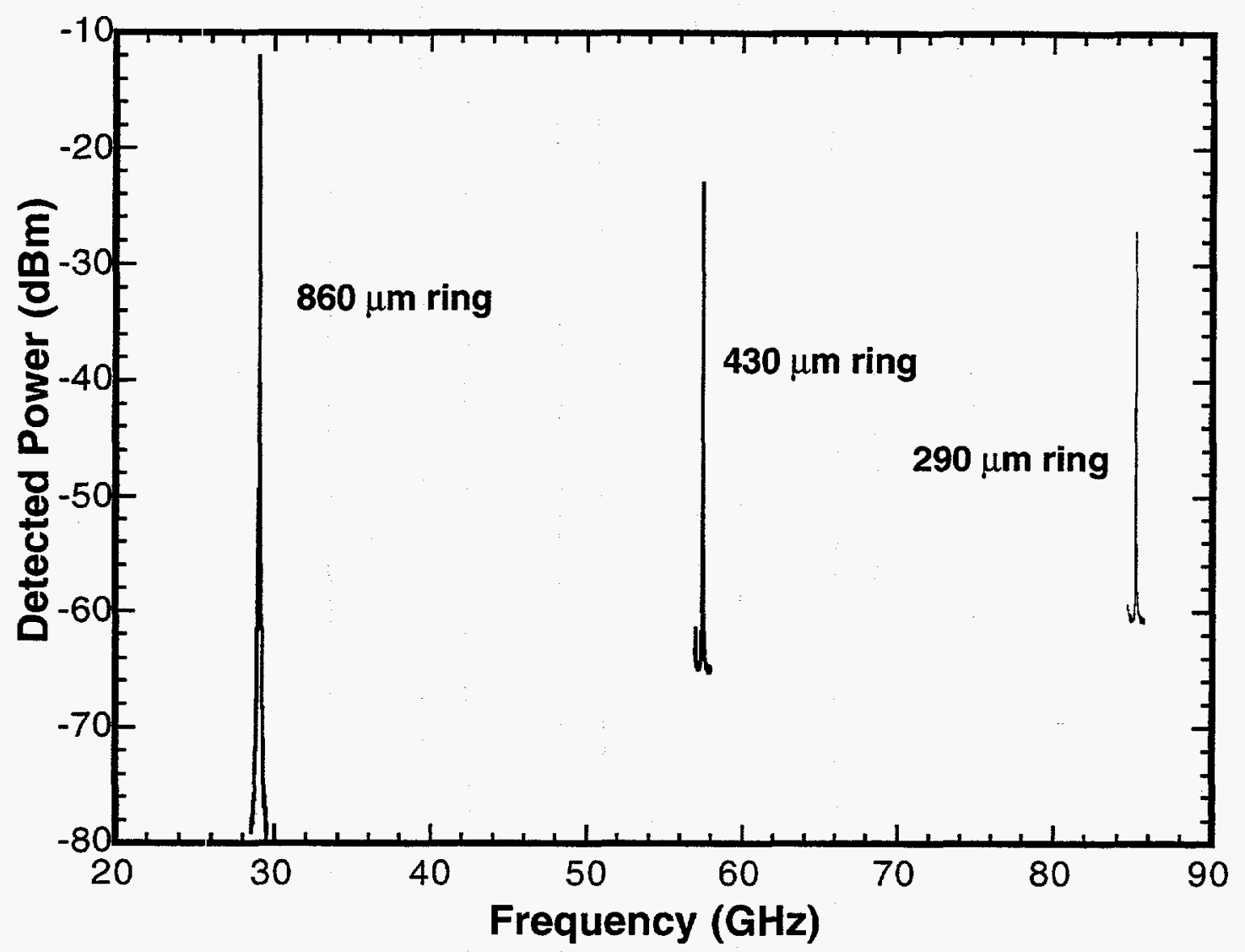

Figure 6: Measured performance of three different mm-wave signal generation PICs. Labeled ring dimensions are the diameter of ring laser used in the PIC to obtain the corresponding signal frequency.

Gain of the optical amplifier was measured under $\mathrm{CW}$ operation using the same bias current indicated in Table 1. Gain measurement were made using the two different amplifier sections to characterize laser performance without an amplifier and with one active amplifier section. According to this procedure, laser output versus current data was collected under two conditions: (1) using the first segment of the two-section amplifier as a reverse biased detector, (2) biasing the first segment with a constant current of $\sim 70 \mathrm{~mA}$ while using the second segment as a reverse biased detector. Gain of the first amplifier segment is then directly determined by the ratio of the measured photocurrents. CW gain resulting from these measurement was in the range of 3 to $4 \mathrm{~dB}$ per $0.5 \mathrm{~mm}$ amplifier segment. These values are only approximations of the actual gain under mode-locked operation. The mode-locked pulses will effectively bleach the inverted carrier population within the amplifier through simulated recombination, obtaining gain from electron-hole 
pairs with the correct energy. However, the pulses are short enough that insufficient time is available for higher-energy carriers to replace those removed from the bands by the pulse before it moves out of that portion of the amplifier. Thus the gain of such a short pulse is limited to that available from the inverted carrier population in place before the pulse passes through the amplifier. As a result, at any bias current sufficient to fill the bands above energies accessible by the pulse, the available gain will be constant. This phenomenon was, in fact, observed during PIC characterization. In contrast, CW gain measurements take advantage of carrier relaxation within the energy bands and exhibit monotonically increasing gain, within certain limits, as injection current is increased. Gain of our amplifiers was measured at the same bias current used for pulsed operation so as to minimize differences in gain in pulsed and CW operation. Even so, the data is best considered an approximation.

\section{Discussion}

The bias currents and voltages used for these measurements were optimized for maximum available detected power at the output transmission line. The power output of $12 \mathrm{dBm}$ at $30 \mathrm{Ghz}$ is consistent with a peak power of $0.2-2 \mathrm{~mW}$ extracted from the saturable absorber. This value assumes a pulse with between 1 and 10 ps. Similarly, -23 $\mathrm{dBm}$ corresponds to a peak power of $8-80 \mu \mathrm{W}$ extracted by the WGPD. Using a $10 \%$ conversion efficiency at the WGPD and $3 \mathrm{~dB}$ gain contributed by the amplifier, the peak power coupled out of the laser at the Y-junction is roughly $35-350 \mu \mathrm{W}$. These peak power levels are consistent with our previous results using optical autocorrelation measurements. In those experiments $110 \mathrm{~mW}$ peak power was obtained in a 1 ps pulse under optimal conditions for narrow pulse formation. Since the mm-wave PIC uses a photodiode optical-to-electrical converter, the operating point for maximum detected electrical power is expected to create wider pulses (up to $10 \mathrm{ps)} \mathrm{at} \mathrm{lower} \mathrm{peak} \mathrm{power} \mathrm{(} \sim 1$ $\mathrm{mW}$ ). Generation of the wider pulses reduces the high-frequency spectral content of the optical pulse train allowing the photodiode to more efficiently convert the optical pulse train to an electrical output signal.

The previous estimates assume that all of the optical pulse power absorbed along the length of the WGPD is converted to photocurrent at the fundamental pulse frequency. Generation of power only at the fundamental frequency requires photogeneration and transport of carriers within the WGPD to be sufficiently slow that power contained in the harmonic frequencies of the optical pulse train is effectively converted to the fundamental by the WGPD. Since the harmonic frequencies are at or above $120 \mathrm{GHz}$, we are unable to directly measure the output spectrum of the WGPD. However, assuming complete conversion to the fundamental frequency does place a lower limit on the peak pulse intensity and an upper limit on frequency generation efficiency. For example, if half of the power of the electrical WGPD output was carried by harmonic frequencies, the required peak optical pulse power would be twice the value calculated for complete conversion to the fundamental frequency. The higher, $-12 \mathrm{dBm}$, signal output at $29.1 \mathrm{GHz}$ is partially due to the fact that the signal is taken from the saturable absorber. The saturable absorber is inside the ring cavity where the circulating peak pulse power is higher than the pulse power coupled out by the y-junction.

The focus of this work has been to demonstrate the feasibility of mm-wave signal generation using a mode-locked ring laser PIC. It is expected that extracted signal levels may be increased as a number of design elements have not been optimized. Output power 
of these circuits is influenced by a number of factors including the internal circulating power of the ring, the amount of power coupled out of the ring, gain of the amplifier and the efficiency of the photodiode. Use of reflective facet output couplers 7 in place of $\mathrm{Y}$ junctions may be expected to provide a greater degree of control in establishing the ratio of output-coupled power to circulating power. Design of the ring laser could then be optimized for maximum power extraction. In addition, depending on the degree to which the photodiode may reproduce the harmonic content of the optical pulse train, pulse shape and width are important factors in determining power output. Wider pulses, up to a duty cycle of approximately 50\%, could improve the output power at the fundamental frequency by as much as $10 \mathrm{~dB}$. Such pulse broadening may be achievable using grating or waveguide-coupler filters within the ring cavity to reduce the lasing spectral bandwidth. Improvements in amplifier gain, detector efficiency and detector power handling capability would also increase the output power of the PIC. Use of a TWPD would increase the output by as much as a factor of 10 at these demonstration frequencies and may be required above $100 \mathrm{GHz}$ due to the poor WGPD efficiency. A flared amplifier with one or more photodiodes operating in parallel at the wide amplifier output end may result in dramatic power enhancements. Finally, pulse-to-pulse timing jitter could be reduced to the femtosecond $\left(10^{-15} \mathrm{~s}\right)$ regime through the use of an external electronic phase-lock loop. Such a phase-lock loop would provide electronic feedback from the pulse output to the saturable absorber section so as to stabilize the pulse repetition frequency.

\section{Conclusion}

In summary, we have demonstrated a new type of PIC for direct generation of mmwave frequencies. This PIC integrates a passively mode-locked semiconductor ring laser with an optical amplifier and high-speed waveguide photodiode. By generating, amplifying and detecting a train of optical pulses, this circuit has been used to generate -23 and $-27 \mathrm{dBm}$ of mm-wave power at 57.5 and $85.2 \mathrm{GHz}$ respectively. Direct sampling of the saturable absorber has generated $-12 \mathrm{dBm}$ at $29.1 \mathrm{GHz}$. PICs using this concept can used in a wide variety of applications where a very compact, lightweight $\mathrm{mm}$-wave source is required.

\section{Acknowledgments}

The authors would like to thank D. Tibbetts-Russell, B. Fuchs for technical assistance. This work was supported by United States Department of Energy under Contract DEAC04-94AL85000. Sandia is a multiprogram laboratory operated by Sandia Corporation, a Lockheed-Martin Company, for the United States Department of Energy. 


\section{References}

[1] J. P. Hohimer and G. A. Vawter,"Passive mode locking of monolithic semiconductor ring lasers at $86 \mathrm{GHz}$," Appl. Phys. Lett., vol. 63, pp. 1598-1600, 1993.

[2] V. M. Hietala, G. A. Vawter, T. M. Brennan and B. E. Hammons,"Traveling-wave photodetectors for high-power large-bandwidth applications," IEEE Trans. on Microwave Th. and Tech., vol. 43, pp. 2291-2297, 1995.

[3] K. S. Giboney, R. L. Nagarajan, T. E. Reynolds, S. T. Allen, R. P. Mirin, M. J. Rodwell and J. E. Bowers,"Travelling-wave photodetectors with $172-\mathrm{GHz}$ bandwidth and $76 \mathrm{GHz}$ bandwidth-efficiency product," IEEE Phot. Technol. Lett., vol. 7, pp. 412414, 1995.

[4] L. Y. Lin, M. C. Wu, T. Itoh, T. A. Vang, R. E. Muller, D. L. Sivco and A. Y. Cho,"Velocity-Matched Distributed Photodetectors with High-Saturation power and large bandwidth," IEEE Phot. Technol. Lett., vol. 8, pp. 1376-1378, 1996.

[5] J. C. Zolper, A. G. Baca and S. A. Chalmers,"Thermally Stable Oxygen Implant Isolation of p-type AlGaAs," Appl. Phys. Lett., vol. 62, pp. 2536-2538, 1993.

[6] R. P. Bryan, J. J. Coleman, L. M. Miller, M. E. Givens, R. S. Averback and J. L. Klatt,"Impurity induced disordered quantum well heterostructure stripe geometry lasers by MeV oxygen implantation," Appl. Phys. Lett., vol. 55, pp. 94-96, 1989.

[7] J. P. Hohimer, G. R. Hadley and G. A. Vawter,"Semiconductor Ring Lasers With Reflection Output Couplers," Appl. Phys. Lett., vol. 63, pp. 278-280, 1993. 


\section{DISTRIBUTION:}

15 MS0603 Allen Vawter, 1314

1 MSO874 Vince Hietala, 1342

1 MSO603 Alan Mar, 1312

1 MS0603 John Zolper, 1314

2 MS0161 John Hohimer, 11500

$1 \quad$ MS0603 Peter Esherick, 1314

1 MS0603 Tom Zipperian, 1313

1 MS0603 Del Owyoung, 1312

1 MS1079 Al Romig, 1300

2 MS0121 LDRD Office, 10402

1 MS9018 Central Technical Files, 8940-2

5 MS0899 Technical Library, 4414

2 MS0619 Review + Approval Desk, 12690

for DOE/OSTI 